\title{
Coincidence of abandoned settlements and climate change in the Xinjiang oases zone during the last 2000 years
}

\author{
JIA Dan, "FANG Xiuqi, ZHANG Chengpeng \\ Faculty of Geographical Science, Beijing Normal University, Beijing 100875, China
}

\begin{abstract}
The study on the relationship of abandoned settlements and climate change in the oases could provide a historical reference for understanding human responses to present and future global warming in the arid zone. A total of 554 abandoned historical settlements in Xinjiang Uygur Autonomous Region, China, were used to examine the relationship between abandoned settlements and temperature change over the past 2000 years. The analysis covered dynastic epochs from the Han Dynasty (206BC-220AD) to the Qing Dynasty (1644AD$1911 A D$ ) in the oases of Xinjiang. Greater density of settlements was found at the oases larger than $2000 \mathrm{~km}^{2}$, which were more stable and less sensitive to climate change compared to smaller oases. Settlements flourished at small oases and the middle and lower reaches of rivers during warm periods and shrank back to piedmont basins and upstream alluvial fans during cold periods. These results demonstrated responses of oasis agriculture to climate change.
\end{abstract}

Keywords: abandoned settlements; climate change; oasis; Xinjiang; the last 2000 years

\section{Introduction}

More and more attention has been paid to the role of past climate change as a driving force of human disruption (Berglund, 2003; Buckley et al., 2010), including changes in subsistence patterns and the catastrophic collapse of societies (Zhang et al., 2007). Many studies have identified coincidence of climate change and major historical events recorded in documents and archaeological evidence (Buntgen et al., 2011; Haug et al., 2003). The flourishing European civilization of the Roman Empire and the Medieval period coincided with warm climates, whereas the collapse of the Roman Empire and the Great Migration coincided with cold climates (Buntgen et al., 2011). The rise and fall of civilizations has also been found to be related to climate change or extreme events in many other parts of the world, such as South America (Haug et al., 2003; Kennett et al., 2012), the Southwestern

Received: 2016-11-03 Accepted: 2017-03-16

Foundation: National Natural Science Foundation of China, No.41371201, No.41430528; Project of Global Change, No.2010CB950103

Author: Jia Dan (1991-), PhD Candidate, specialized in the research of climate change and human adaptation. E-mail: Jiadan2012@163.com

"Corresponding author: Fang Xiuqi, Professor, E-mail: xfang@bnu.edu.cn 
United States (Polyak and Asmerom, 2001), the Middle East (Issar and Zohar, 2007), Southwestern Europe (Carrión et al., 2007), the Mediterranean world (Butzer, 2005), and Greenland (Gilbert et al., 2008; Dugmore et al., 2009). In the monsoon climate-dominated China, many studies have found that compared with warm periods, the agrarian economy in cold periods was more unstable and war increased (Fang et al., 2013; Wei et al., 2014; Wei et al., 2015; Xiao et al., 2014; Zheng et al., 2014).

Xinjiang Uygur Autonomous Region in Northwest China is an important window for China facing the West. The abandoned settlements in this region are important records of human civilization that could be used for better understanding the relationship between climate change and human civilization in the historical period. Studies on the abandoned settlements in this region began in the 19th century. It was made sure that the abandonments were mainly concentrated in four periods: the 4th-5th century, 7th-8th century, about the 11 th century and the 13th century (Zhong et al., 2004; Shu et al., 2007). The case studies in this region mainly focused on specific settlements. The demise of Loulan city was caused by climate cyclical change and river diversion in the 3rd century in the Lop Nur region (Wang, 2010). Around the Taklamakan Desert, the demise of Haitou and Ruoqiang settlements was caused by land desertification (Shu et al., 2007), the demise of Yuansha city was caused by river migration and oasis declination, the same situation was also for the Jingjue city (Niya) (Hou, 2009; Zhang et al., 2011). In conclusion, the researches on the reasons of these settlements abandonment has mainly focused on increasing aridity of the climate, river diversion, desertification, and social unrest (Han et al., 2014; Zhong et al., 2004).

In general, the causes of oasis evolution in the Tarim Basin are discussed from two aspects containing climate change and human activities on different temporal scales. During the historical period, climate change was regarded as one of the principal factors influencing the oasis evolution as well as human activities that the socio-economic prosperity of oases and their expansion occurred largely during warm periods, while desertification and the deterioration of natural environment mainly occurred during cool periods (Hong et al., 2003).

In this paper, we use archaeological data and paleo-climatic sequence to explore the role of climate change in the spatio-temporal distribution of abandoned settlements in the Xinjiang oases zone. We hope that it could provide a historical reference for responses to present and future global warming.

\section{Data and methods}

Xinjiang oases zone is located in deep hinterland and rarely meets the warm and moist air of summer monsoon (Xu, 2010). Thus, precipitation is sparse in the Tarim Basin with continuous increase in climate aridity (Zhao et al., 2015). There are three types of oases, including piedmont alluvial-proluvial fan oases, middle reaches of rivers oases and river terminal lake oases. The latter two types are more affected by river diversion and human activities, but the oases in piedmont alluvial-proluvial fans are more sensitive to climate change, because they depend on the supply of glacier and snow meltwater (Kutuzov and Shahgedanova, 2009; Ding et al., 2006). Settlements used in this paper mainly located in piedmont alluvial-proluvial fans. The fluctuation of melting water from glacier and snow determined the evolution of oases and could directly influence the rise and fall of settlements in the oases, especially those developed on the smaller oases formed by shorter rivers 
in front of lower mountains. In general, the runoff flowing into the oasis could increase under the warm climate due to more glacier and snow meltwater and decrease under the cool climate. Based on the above mechanism, we are committed to studying the relationship between temperature fluctuations and abandoned settlements variation in the last 2000 years.

\subsection{Abandoned settlements}

Settlements were usually built on oasis with flat terrain and sufficient water supply to be suitable for farming. The abandoned settlements we investigated in this paper were located in Xinjiang $\left(73^{\circ} \mathrm{E}-90^{\circ} \mathrm{E}, 34^{\circ} \mathrm{N}-50^{\circ} \mathrm{N}\right.$, the boundary between Northern and Southern Xinjiang is $42.5^{\circ} \mathrm{N}$ ), which contains two basins (the Tarim Basin and the Junggar Basin) bounded by three mountain ranges (the Altai Mountains, Tianshan Mountains, and Kunlun Mountains). The abandoned settlements we used were extracted from the Atlas of Chinese Cultural Relics: Xinjiang Volume (Elken, 2012), which was compiled and edited by the State Administration of Cultural Heritage and contains a huge amount of original information acquired from archaeological surveys. We imported each county map of the atlas in ArcGIS 9.3. Then, image registration was used to each map in accordance with the administrative boundaries. We extracted the location of each settlement from the map and recorded the name. The age of each settlement (as provided in the respective volume of the atlas) was consistently as assigned. The temporal resolution of settlements was defined as dynasty. In total, 554 abandoned settlements had been recorded in the database.

The study period ranges from $206 \mathrm{BC}$ to $1911 \mathrm{AD}$, which is to say from the Han Dynasty (206BC-220AD) to the Qing Dynasty (1644AD-1911AD). In periods when China had more than one regime at the same time, we used the major dynasty to indicate the time. For example, abandoned settlements belonging to the dynasties of Liao (916AD-1125AD), Jin (1115AD-1234AD) and Western Xia (1038AD-1227AD) were unified under the Song Dynasty (960AD-1279AD). In order to make the number of the abandoned settlements between the dynasties less affected by the differences in length of the dynasties, we excluded the dynasties shorter than 80 years from the statistics, including the Three Kingdoms (220AD-280AD), Sui Dynasty (581AD-618AD), and Five Dynasties (907AD-960AD). These dynasties were too short in length and in a period of turmoil and transition compared with other longer unified dynasties. After data cleaning, only eight dynasties named Han (206BC-220AD), Two Jin (Western Jin and Eastern Jin, 280-420AD), Northern and Southern Dynasties (420-589AD), Tang (618-907AD), Song (960-1279AD), Yuan (1279-1368AD), Ming (1368-1644AD) and Qing dynasties (1644-1911AD) were remained in the research. A total of 554 abandoned settlements were used for calculation (Figure 1a).

\subsection{Temperature series}

The temperature series used in this paper were reconstructed by tree-ring width chronology based on Qilian junipers from the upper tree line of the A'nyemaqen Mountains (99 $30^{\prime} \mathrm{E}$, $35^{\circ} 15^{\prime} \mathrm{N}$ ), on the eastern Tibetan Plateau (Chen, 2016), which had sufficient length and were relatively close to the study area. Correlation analysis showed that the chronology was significantly negatively correlated with April-June maximum temperature at nearby meteorological stations. The 2274-year April to June maximum temperature was reconstructed according to correlation analysis between tree-ring width chronology and meteorological data. The regression model can explain $37.9 \%$ of the total variance for the whole calibration pe- 
riod of 1960-2012 (Chen, 2016) (Figure 1b).

The Correlation map shows that the temperature sequence of the A'nyemaqen Mountains can represent the temperature of the Tarim Basin $\left(34^{\circ} \mathrm{N}-40^{\circ} \mathrm{N}, 75^{\circ} \mathrm{E}-90^{\circ} \mathrm{E}\right)$ with the correlation coefficient larger than 0.3 (Chen, 2016). Fluctuation of the reconstructed temperature of the A'nyemaqen Mountains (Chen, 2016) is Comparable with that of several large-scale temperature reconstructions for China (Ge et al., 2013), Europe (Buntgen et al., 2011) and Northern Hemisphere. There are coherent changes among all these temperature series for cold period as the 'Little Ice Age' (from approximately the 16th to the 19th century AD) and the Dark Ages (approximately the 3rd to the 5th century AD), as well as the warm periods. Such a coherent change implies that the temperature change in Xinjiang should be the same, because it is located between eastern China and Europe, and north to the Qinghai-Tibet Plateau. Compared with the other temperature series lasted for more than 2000 years, the temperature series of the A'nyemaqen Mountains is closer to the study area. Thus, it could be used to represent the temperature change of the study area in this paper.

Based on the reconstructed temperature of the A'nyemaqen Mountains (Chen, 2016), we calculated the average temperature anomalies for each of the 8 dynasties to match the temporal resolution of the settlements during the last 2000 years (Table 1).
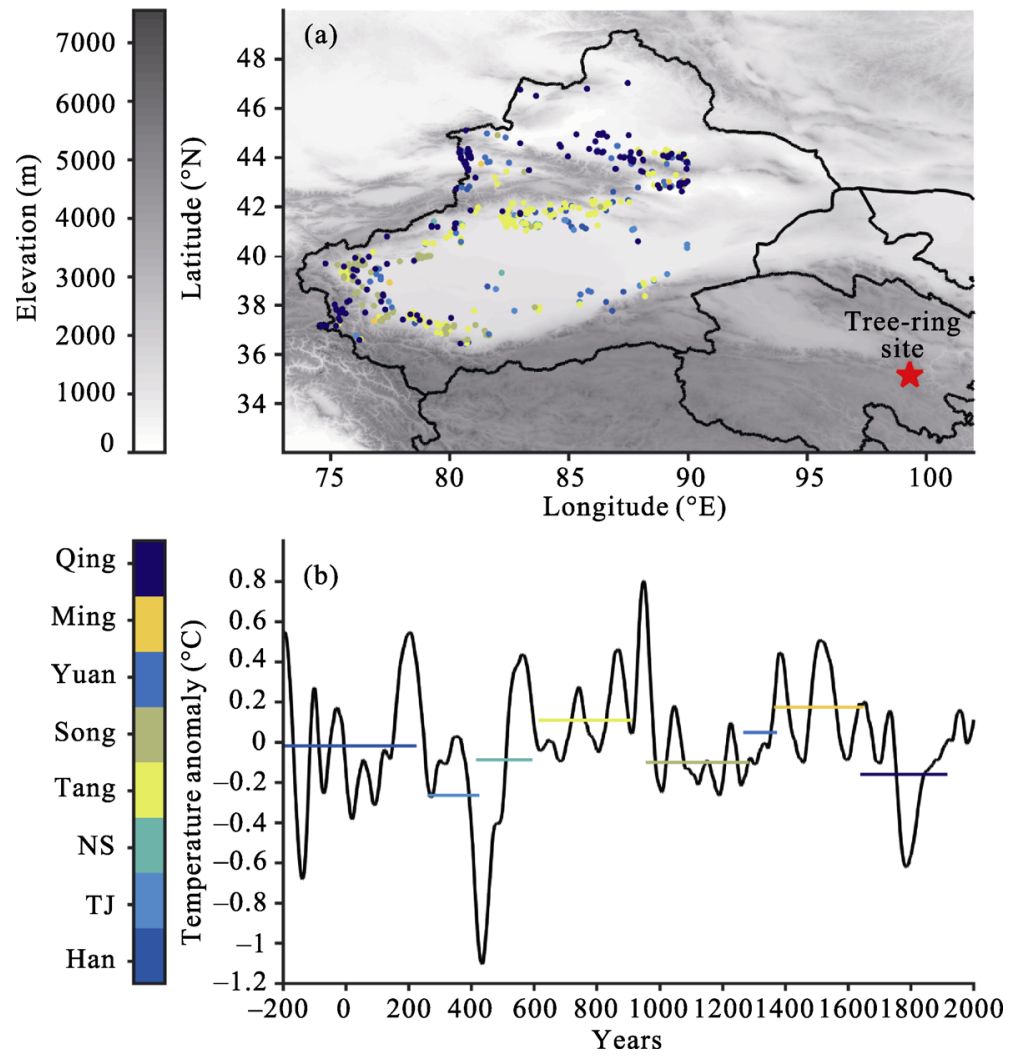

Figure 1 Overview of the study area (a) and the temperature sequence of the past 2000 years (b). In (a), colored dots indicate abandoned settlements in corresponding dynasties. The star is the location of temperature series of the A'nyemaqen Mountains. In (b), the black solid line represents a 30-year moving average reconstructed April-June maximum temperature by tree-ring width chronology in the A'nyemaqen Mountains (red pentagram) (Chen, 2016); colored segments represent average temperature in each dynasty and the length of the segments indicates the length of the dynasties. In the abbreviation of the dynasty marked in the legend, TJ means Two Jin Dynasties (280-420AD) and NS means Northern and Southern Dynasties (420AD-589AD). 
Table 1 Temperature anomaly and the number of settlements in each dynasty in Xinjiang during the last 2000 years

\begin{tabular}{lcccc}
\hline \multicolumn{1}{c}{ Dynasty (years) } & Length of & \multicolumn{2}{c}{ Number of settlements } & \multirow{2}{*}{$\begin{array}{c}\text { Temperature } \\
\text { anomaly }\left({ }^{\circ} \mathrm{C}\right)\end{array}$} \\
\cline { 3 - 4 } & dynasty (years) & Northern Xinjiang & Southern Xinjiang & -0.0179 \\
Han (206BC-220AD) & 426 & 15 & 99 & -0.2632 \\
Two Jin (280AD-420AD) & 140 & 5 & 86 & -0.0868 \\
Northern and Southern Dynasties & 169 & 13 & 95 & 0.1096 \\
(420AD-589AD) & 289 & 62 & 237 & -0.0994 \\
Tang (618AD-907AD) & 319 & 36 & 94 & 0.0493 \\
Song (960AD-1279AD) & 89 & 38 & 16 & 0.1748 \\
Yuan (1279AD-1368AD) & 276 & 9 & 7 & -0.1595 \\
Ming (1368AD-1644AD) & 267 & 86 & 57 & \\
Qing (1644AD-1911AD) & & & & \\
\hline
\end{tabular}

\subsection{Methods}

In Xinjiang, abandoned settlements were generally distributed on the oases of different sizes. For spatial comparison of the settlements between the dynasties, we draw dynastic settlements in each dynasty with topography and rivers. For calculating the number of settlements, we divided Xinjiang into two parts of north and south by $42.5^{\circ} \mathrm{N}$ and calculated the number of settlements of 8 dynasties in each part. We compared the temperature and the number of settlements in Northern and Southern Xinjiang in each dynasty.

Water is the basis for the survival of oasis in the arid area. The change of water amount could directly affect the prosperity and disappearance of an oasis (Sun, 2015; Hou, 2009; Liang and Zhou, 2010; Liu, 2003). The water resources in the oases of the Tarim Basin mainly depend on the river supply. The river with the larger runoff can provide more abundant water resources and maintain bigger oases (Liang and Zhou, 2010; Yang, 2014). In this paper, we test the relationship between the number of settlements and oasis area of each river basin in Xinjiang. According to the division on the watersheds in the Tarim Basin (Liang and Zhou, 2010), we calculated the number of abandoned settlements for each of the 16 river basins and used linear regression to analyse the relation between oasis area and the number of settlements in each river basin, in order to understand the relation between the number of abandoned settlements and oasis area.

\section{Results}

\subsection{Spatial and temporal changes in settlements under different climatic conditions}

During the warm period of the Han Dynasty, there were a total of 99 known settlements located in Southern Xinjiang, as seen in Table 1. Most of them concentrated in large oases of the piedmont alluvial-proluvial fans. The number of settlements in Northern Xinjiang was only 15, with almost blank in Junggar Basin (Figure 2a).

Compared to the Han Dynasty, the Jin Dynasty and Northern and Southern Dynasties were in a cold period. The Jin Dynasty featured 86 settlements in Southern Xinjiang and 5 settlements in Northern Xinjiang. The settlements originally distributed around small river basins in Southern Xinjiang had disappeared in the Jin Dynasty. A total of 95 settlements located in Southern Xinjiang during the period of Northern and Southern Dynasties and only 
15 settlements distributed in Northern Xinjiang under a slight increase in temperature (Table 1). Overall, the locations of the settlements in the Northern and Southern period remained roughly similar to those in the Jin Dynasty (Figure 2b).
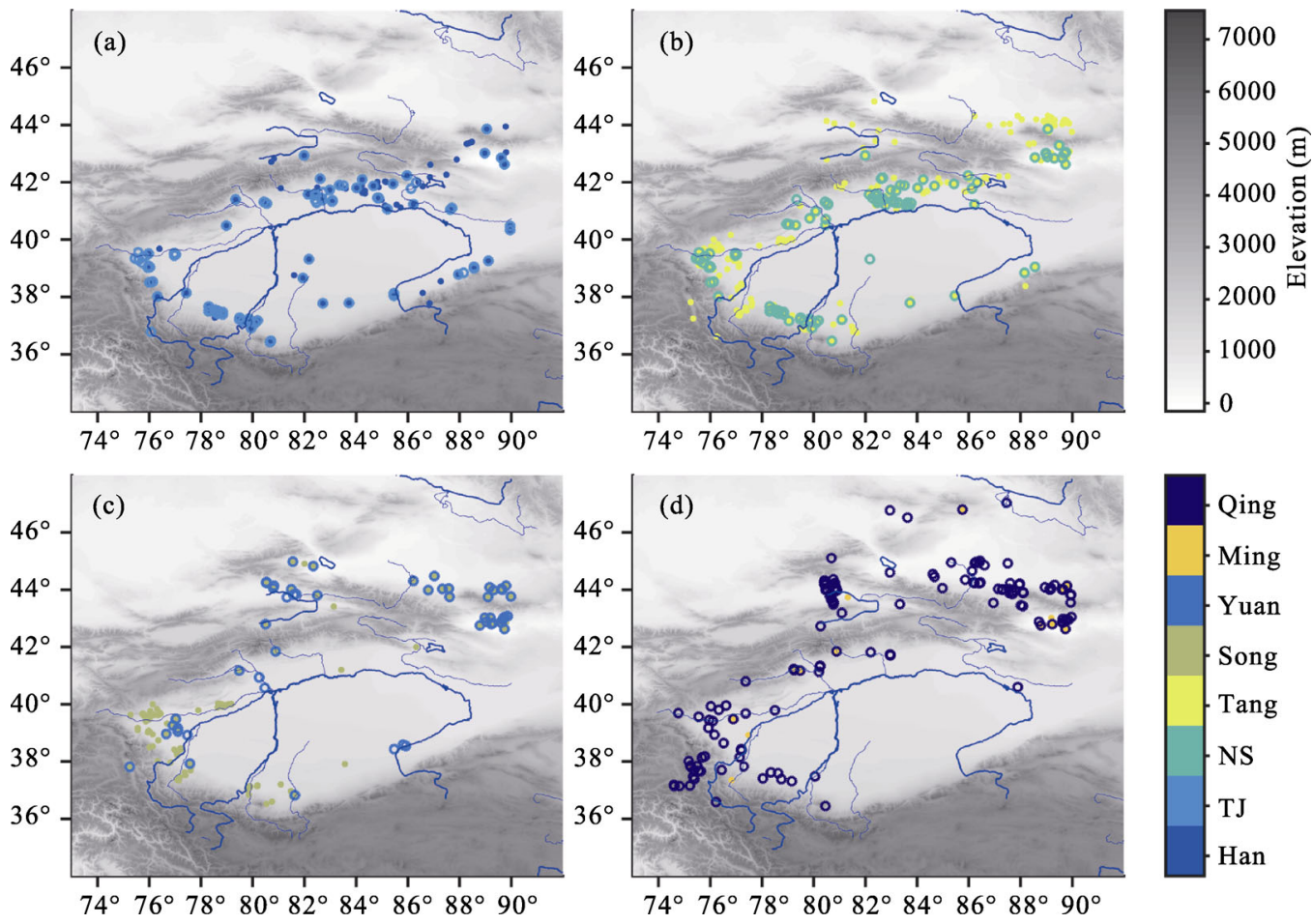

Figure 2 Spatial distribution of settlements over 8 dynasties in Xinjiang, with topography (colorful dots represent settlements in the corresponding dynasty; the blue line indicates the location of the rivers). (a) Settlements in Han and Two Jin Dynasty (TJ); (b) Settlements in Northern and Southern Dynasty (NS) and Tang Dynasties; (c) Settlements in Song and Yuan dynasties; (d) Settlements in Ming and Qing dynasties.

During the history of Xinjiang in the last 2000 years, the Tang Dynasty was definitely the most prosperous period when was also a warm period. In the Tang Dynasty, the number of settlements increased dramatically to 237 in Southern Xinjiang and 62 in Northern Xinjiang with the rise of temperature. The Yarkand river basin in Southern Xinjiang witnessed the appearance of a large number of settlements. This increase also appeared in the Yili river valley and area north of Bogda Mountains in Northern Xinjiang. From the Tang to the Song Dynasty, as the temperature decreased, the number of settlements dropped substantially to 94 and 36 in Southern and Northern Xinjiang respectively (Figure 2c).

From the Song to the Yuan Dynasty, with slight increase in temperature, settlements reappeared at small oases such as Qiemo. But the total number of settlements in the Yuan Dynasty was less than that in the Song Dynasty with 16 and 38 in Southern and Northern Xinjiang respectively, that might be because Xinjiang was actually controlled by Chagatai Khanate in the Yuan Dynasty. However, from the Yuan to the Ming Dynasty, even as the temperature continued rising, the number of settlements still decreased to 7 and 9 in Southern and Northern Xinjiang (Figure 2d), that might be because the central government of China lost its jurisdiction on Xinjiang during the Ming Dynasty (Fang, 1989). 
From the Ming to the Qing Dynasty, as the temperature decreased drastically, the number of settlements still increased, which was directly related to the fact to the region was under the jurisdiction of the central government of China again, and the policy of cultivation for the military by the Qing government (Fang, 1989). The number of settlements was 57 and 85 in Southern and Northern Xinjiang respectively.

During the Yuan, Ming, and Qing dynasties, although the number of settlements increased, the spatial distribution of them still concentrated in the intermontane basins at higher elevations and upstreams of the alluvial-proluvial fans (Figure 2). Settlements in small oases east of the Keriya River located in the piedmont areas of northern Kunlun Mountains were all abandoned in the Ming and Qing dynasties within the Little Ice Age (Table 1). Even settlements located at larger river basins like Kuqa and Korla also continued into obsolescence during the Yuan, Ming, and Qing dynasties (Figure 2d). Before the Qing Dynasty, the number of settlements in Northern Xinjiang is less than that in Southern Xinjiang, mainly due to the long-term nomadic status of the northern part.

\subsection{The stability of the settlements to temperature change in different sizes of oases}

The Tarim Basin could be divided into 16 watersheds (Liang and Zhou, 2010). We calculated the number of abandoned settlements in each one (Table 2). In general, larger river basins for more water supply supported more settlements than smaller ones (Figure 3).

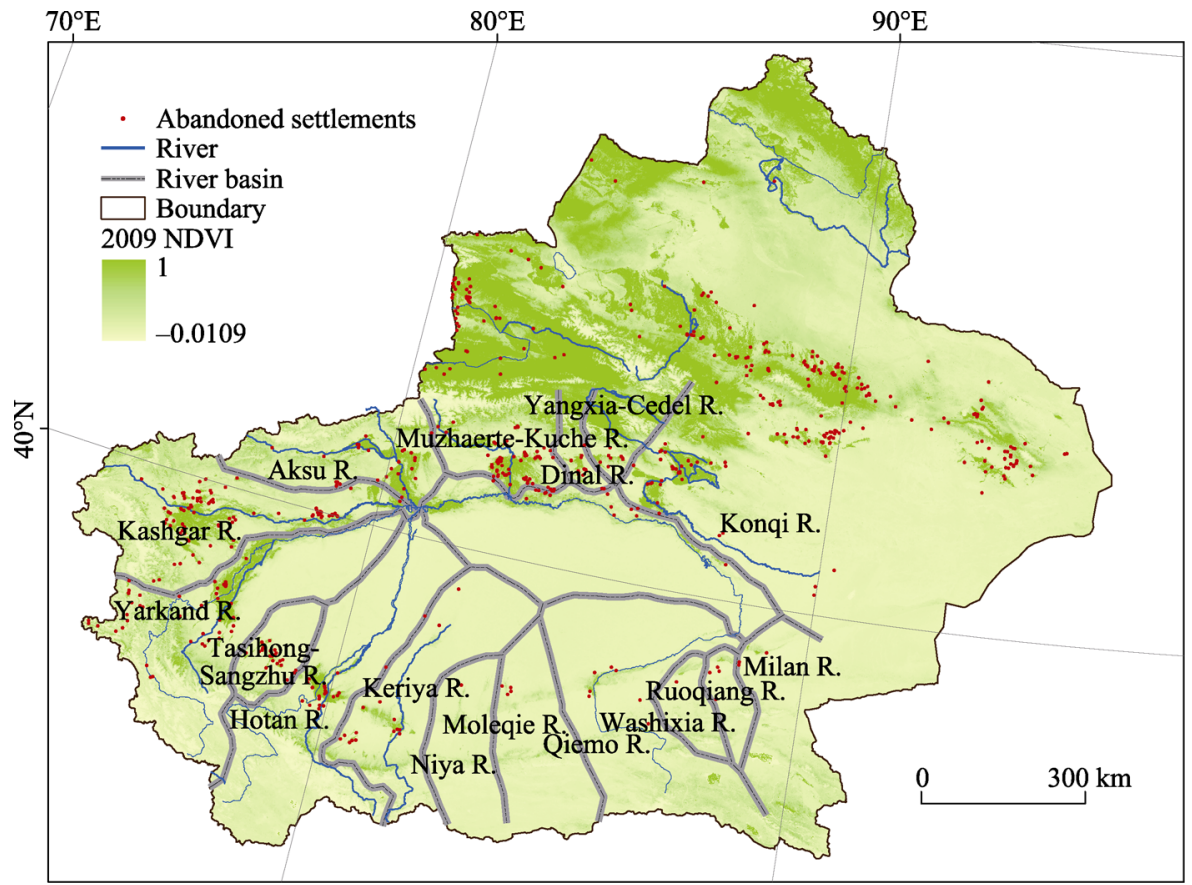

Figure 3 Spatial distribution of abandoned settlements in 16 river basins in the Tarim Basin. NDVI in 2009 was used to indicate vegetation distribution in Xinjiang. This dataset was provided by International Scientific \& Technical Data Mirror Site, Computer Network Information Center, Chinese Academy of Sciences. (http://www. gscloud.cn).

A clear positive linear relation between the area of oasis and the total number of abandoned settlements in the Tarim Basin with $0.91(P<0.01)$ correlation coefficient was found. 
The regression showed that when size of oasis expanded by $1000 \mathrm{~km}^{2}$, the number of settlements could increase by 7 (Figure 4b).

Table 2 Area of oases (Liang and Zhou, 2010) and the number of abandoned settlements of each river basin in the Tarim Basin

\begin{tabular}{lcc}
\hline \multicolumn{1}{c}{ Name of river basin } & Area of oasis $\left(\mathrm{km}^{2}\right)$ & Number of abandoned settlements \\
\hline Kashgar river & 12719.54 & 91 \\
Yarkand river & 9951.36 & 28 \\
Aksu river & 7025.53 & 64 \\
Muzart-Kuche river & 6824.42 & 22 \\
Hotan river & 3138.23 & 37 \\
Konqi river & 3021.23 & 15 \\
Cele-kaxi-Keriya river & 1732.43 & 6 \\
Qiemo river & 757.40 & 14 \\
Dinal river & 712.51 & 8 \\
Yangxia-Cedel river & 582.66 & 23 \\
Tasihong-Sangzhu river & 506.27 & 1 \\
Niya river & 257.31 & 4 \\
Ruoqiang river & 80.69 & 4 \\
Milan river & 66.44 & 3 \\
Washixia river & 58.68 & 21.19 \\
Bositantuoge lake-Alamilan-Moleqie river & & 4
\end{tabular}

The gray color indicates oasis area less than $2000 \mathrm{~km}^{2}$.
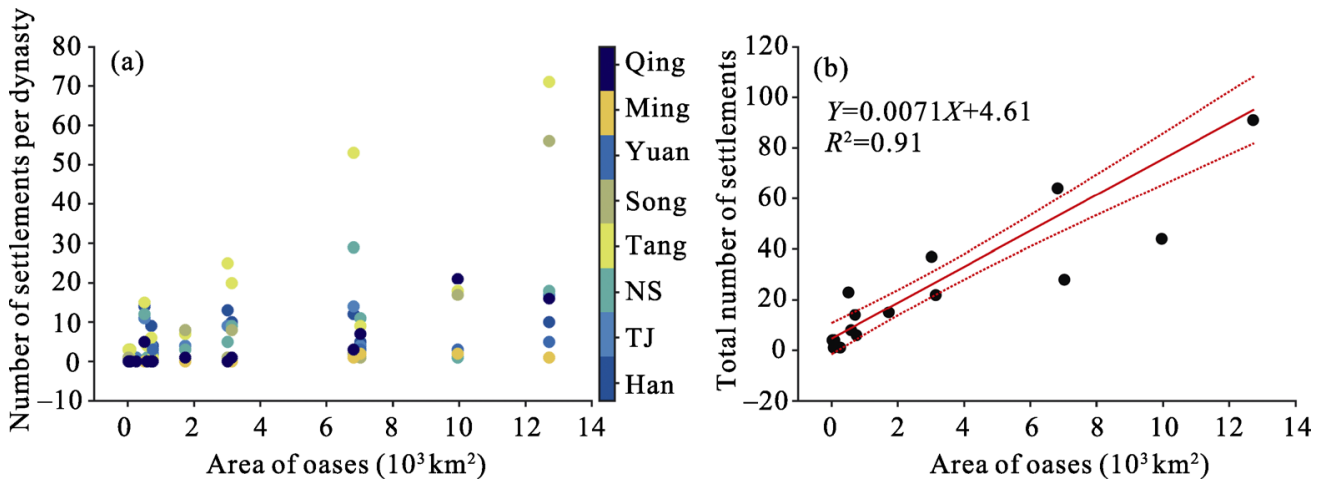

Figure 4 The relation between area of oasis and number of settlements. (a) Scatter plot between area of oasis and number of settlements in corresponding dynasty (colored solid dots represent corresponding dynasty); (b) Linear regression between area of oasis and total number of abandoned settlements in the Tarim Basin.

Beside the total number of abandoned settlements, we also calculated the number of settlements of each oasis in each dynasty. The scatter plot showed that the Tang Dynasty was the most prosperous period in the Tarim Basin during the past 2000 years, with settlements distributed across oases of different sizes and increasing significantly and steadily with the increase in size of the oases. The scatter plot also showed that the number of settlements in each dynasty fell to less than 20 when the oasis area was less than $2000 \mathrm{~km}^{2}$ (Figure $4 \mathrm{~b}$ ), which were prone to abandoned land due to climate deterioration (Table 2). When temperature 
decreased, the settlements distributed in small oases, such as the Milan, Ruoqiang, Washixia, and Niya basins, were soon abandoned, whereas settlements located on large oases with sufficient glacier water supply were more stable, such as in the Kashgar and Aksu basins.

\section{Conclusions and discussion}

Xinjiang was an important channel to communicate between China and Europe, and had multiple prosperous civilizations in the history. In this study, we created a database of abandoned settlements in Xinjiang from 206BC to 1911AD by extracting data from Atlas of Chinese Cultural Relics: Xinjiang Volume (Elken, 2012). Through the analysis of change of settlements in Xinjiang during the last 2000 years, we concluded that:

1) There were 99 and 15 settlements located in Southern and Northern Xinjiang during the warm period of the Han Dynasty. From the Han Dynasty to the Two Jin, with the temperature drop, the number of settlements decreased to 86 and 5 respectively in Southern and Northern Xinjiang. Slight temperature increase from Two Jin to Northern and Southern Dynasties corresponded to settlement increase to 95 and 13 in Southern and Northern Xinjiang. Until the Tang Dynasty, a significant rise in temperature was accompanied by a large number of settlement increase to 237 and 62 in Southern and Northern Xinjiang. There are 94 and 36 settlements in the Song Dynasty with the temperature decreasing from the Tang to the Song Dynasty. Although the Yuan Dynasty belonged to warm period compared with the Song Dynasty, settlements still reduced to 16 and 38 due to Chagatai Khanate's control. From the Yuan to the Ming dynasty, even as the temperature continued rising, the number of settlements still reduced to 7 and 9 in Southern and Northern Xinjiang, that might be because the central government of China lost its jurisdiction of Xinjiang during the Ming Dynasty. From the Ming to the Qing Dynasty, as the temperature decreased drastically, the number of settlements increased to 57 and 86 in Southern and Northern Xinjiang, which was directly related to the fact that the region was under the jurisdiction of the central government of China again, and the policy of cultivation for the military by the Qing government.

2) The settlements were more stable on the oases larger than $2000 \mathrm{~km}^{2}$ in the Tarim Basin than those on small oases. Historical settlements could be built on the oases in small river basins and the middle and lower reaches of the rivers during the warm periods, and they shrank back to the larger oases during the cold periods over the past 2000 years.

3) There were positive correlations between temperature fluctuation and location of settlements, oasis area, and number of settlements over the last 2000 years. In the Tarim Basin, the number of settlements in each dynasty increased significantly with the increase in size of the oases.

Under the extremely arid conditions of Xinjiang, water affected by climate change is the critical factor for agriculture and human living. We interpret the mechanism of relationship between climate change and abandoned settlements is that colder climate reduced glacier meltwater, shortened rivers, atrophied oases, and intensified desertification, which ultimately resulted in the settlement's abandonment. Unfortunately, the shortage of intermediate information on these links limited our further interpretation on the mechanism.

The establishment and abandonment of settlements have complex influencing factors including military force of central government of China. In this paper, we only consider the coincidence between temperature change and settlement distribution. Other social factors 
and complex mechanism should be studied further in the future.

\section{References}

Berglund B E, 2003. Human impact and climate changes: Synchronous events and a causal link? Quaternary International, 105: 7-12. doi: 10.1016/s1040-6182(02)00144-1.

Buckley B M, Anchukaitis K J, Penny D et al., 2010. Climate as a contributing factor in the demise of Angkor, Cambodia. Proceedings of the National Academy of Sciences of the United States of America, 107: 6748-6752. doi: 10.1073/pnas.0910827107.

Büntgen U, Tegel W, Nicolussi K et al., 2011. 2500 years of European climate variability and human susceptibility. Science, 331: 578-582. doi: 10.1126/science.1197175.

Butzer K W, 2005. Environmental history in the Mediterranean world: Cross-disciplinary investigation of cause-and-effect for degradation and soil erosion. Journal of Archaeological Science, 32: 1773-1800. doi: 10.1016/j.jas.2005.06.001.

Carrión J S, Fuentes N, Samperiz P G et al., 2007. Holocene environmental change in a montane region of southern Europe with a long history of human settlement. Quaternary Science Reviews, 26: 1455-1475. doi: 10.1016/j.quascirev.2007.03.013.

Chen Feng, Zhang Yong, Shao Xuemei et al., 2016. A 2000-year temperature reconstruction in the Animaqin Mountains of the Tibet Plateau, China. The Holocene, 0959683616646187.

Ding Yongjian, Liu Shiyin, Li Jing, 2006. The retreat of glaciers in response to recent climate warming in western China. Annals of Glaciology, 43: 97-105. doi: http://dx.doi.org/10.3189/172756406781812005.

Dugmore A J, Keller C, McGovern T H et al., 2009. Norse Greenland settlement and limits to adaptation. In: Adapting to Climate Change: Thresholds, Values, Governance. Cambridge: Cambridge University Press.

Elken M, 2012. Atlas of Chinese Cultural Relics: Xinjiang Volume. Beijing: Cultural Relics Press.

Fang Xiuqi, Xiao Lingbo, Wei Zhudeng, 2013. Social impacts of the climatic shift around the turn of the 19th century on the North China Plain. Science China Earth Sciences, 56: 1044-1058. doi: 10.1007/s11430-0124487-z.

Fang Yingkai, 1989. The History of Xinjiang Reclamation. Urumqi: Xinjiang Juvenile Publishing House. (in Chinese)

Ge Quansheng, Hao Zhixin, Zheng Jingyun et al., 2013. Temperature changes over the past $2000 \mathrm{yr}$ in China and comparison with the Northern Hemisphere. Climate of the Past, 9: 1153-1160. doi: 10.5194/cp-9-1153-2013.

Gilbert M T, Kivisild T, Grønnow B et al., 2008. Paleo-Eskimo mtDNA genome reveals matrilineal discontinuity in Greenland. Science, 320: 1787-1789. doi: 10.1126/science.1159750.

Han Wenxia, Yu Lupeng, Lai Zhongping et al., 2014. The earliest well-dated archeological site in the hyper-arid Tarim Basin and its implications for prehistoric human migration and climatic change. Quaternary Research, 82: 66-72.

Haug G H, Günther D, Peterson L C et al., 2003. Climate and the collapse of Maya civilization. Science, 299: 1731-1735. doi: 10.1126/science.1080444.

Hou Yongjian, 2009. Niya River, a runoff from West Kunlun Mountains and Niya settlements. The Western Regions Studies, 1: 45-54.

Issar A S, Zohar M, 2007. Climate Change: Environment and History of the Near East. Berlin: Springer.

Kennett D J, Breitenbach S F M, Aquino V V et al., 2012. Development and disintegration of Maya political systems in response to climate change. Science, 338: 788-791. doi: 10.1126/science.1226299.

Kutuzov S, Shahgedanova M, 2009. Glacier retreat and climatic variability in the eastern Terskey-Alatoo, inner Tien Shan between the middle of the 19th century and beginning of the 21 st century. Global and Planetary Change, 69: 59-70. doi: 10.1016/j.gloplacha.2009.07.001.

Liang Jianming, Zhou Jie, 2010. Relationship between oases distribution and stream runoff in the Tarim Basin. Journal of Arid Land Resources and Environment, 24(4): 50-54. (in Chinese)

Liu Shiyin, Sun Wenxin, Shen Yongping et al., 2003. Glacier changes since the Little Ice Age maximum in the 
western Qilian Shan, northwest China, and consequences of glacier runoff for water supply. Journal of Glaciology, 49(164): 117-124.

Nunn P D, Hunter-Anderson R, Carson S T et al., 2007. Times of plenty, times of less: Last-millennium societal disruption in the Pacific Basin. Human Ecology, 35: 385-401. doi: 10.1007/s10745-006-9090-5.

Polyak V J, Asmerom Y, 2001. Late Holocene climate and cultural changes in the Southwestern United States. Science, 294: 148-151. doi: 10.1126/science.1062771.

Shu Qiang, Zhong Wei, Li Cai, 2007. Distribution feature of ancient ruins in south edge of Tarim Basin and relationship with environmental changes and human activities. Journal of Arid Land Resources and Environment, 21(11): 95-100. (in Chinese)

Wan Guoding, 1978. Chinese History Chronology. Beijing: Zhonghua Book Company.

Wang Zhichao, 2010. The changes of Lop Nur Lake and the disappearance of Loulan. Journal of Arid Land, 2: 295-303.

Wei Zhudeng, Fang Xiuqi, Su Yun, 2014. Climate change and fiscal balance in China over the past two millennia. The Holocene, 24: 1771-1784. doi: 10.1177/0959683614551224.

Wei Zhudeng, Rosen A M, Fang Xiuqi et al., 2015. Macro-economic cycles related to climate change in dynastic China. Quaternary Research, 83: 13-23. doi: 10.1016/j.yqres.2014.11.001.

Xiao Lingbo, Fang Xiuqi, Zhang Yujie et al., 2014. Multi-stage evolution of social response to flood/drought in the North China Plain during 1644-1911. Regional Environmental Change, 14: 583-595. doi: 10.1007/s10113-013-0516-5.

Xu Changchun, Chen Yaning, Yang Yuhui et al., 2010. Hydrology and water resources variation and its response to regional climate change in Xinjiang. Journal of Geographical Sciences, 20(4): 599-612.

Yang Yu, Liu Yi, 2014. Spatio-temporal analysis of urbanization and land and water resources efficiency of oasis cities in Tarim River Basin. Journal of Geographical Sciences, 24(3): 509-525.

Zhang D D, Zhang J, Lee H F et al., 2007. Climate change and war frequency in Eastern China over the last millennium. Human Ecology, 35: 403-414. doi: 10.1007/s10745-007-9115-8.

Zhang Feng, Wang Tao, Hamid Y et al., 2011. Hydrological changes and settlement migrations in the Keriya River delta in central Tarim Basin ca. 2.7-1.6 ka BP: Inferred from 14C and OSL chronology. Science China Earth Sciences, 54: 1971-1980.

Zhang Hong, Wu Jianwei, Zheng Qiuhong et al., 2003. A preliminary study of oasis evolution in the Tarim Basin, Xinjiang, China. Journal of Arid Environments, 55(3): 545-553.

Zhao Ji, Fang Xiuqi, Wang Wei, 2015. New Physical Geography of China. Beijing: Higher Education Press. (in Chinese)

Zheng Jingyun., Xiao Lingbo, Fang Xiuqi et al., 2014. How climate change impacted the collapse of the Ming Dynasty. Climatic Change, 127: 169-182. doi: 10.1007/s10584-014-1244-7.

Zhong Wei, Wang Liguo, Li Cai, 2004. Process and characteristics of historical climate and environment changes in southern margin of Tarim Basin. Journal of Desert Research, 24(3): 261-267. (in Chinese)

Zhong Wei, Xiong Heigang, Tiyip T et al., 2001. Historical climate changes in southern Xinjiang. Journal of Geographical Sciences, 11(4): 449-453. 